\title{
Prácticas musicales andinas a comienzos del siglo XXI
}

\section{Julio Mendívil}

Universidad de Viena

julio.mendivil@univie.ac.at

\section{Raúl R. Romero}

Instituto de Etnomusicología - Grupo de Investigación en Musicología

Pontificia Universidad Católica del Perú

rromero@pucp.pe

En las líneas introductorias a su conocida clasificación de instrumentos musicales, Erich von Hornbostel y Curt Sachs llaman la atención sobre el carácter disímil que suele existir entre las codificaciones científicas y el propio objeto de estudio, advirtiendo que, mientras que aquellas suelen ser rígidas y reacias al cambio, el objeto de estudio jamás está exento de transformaciones. Al igual que los instrumentos, las prácticas musicales vivas son propensas a mudar, pues la música - como un hecho social enmarcado en un determinado tiempo y contexto históricos - no es, bajo ninguna circunstancia, plenamente independiente de los vaivenes de las sociedades en que se desarrollan. La música que se practica en los Andes no es excepción alguna. Aunque numerosos intérpretes o consumidores suelen imaginarla como una fuerza inalterable, legada desde tiempos pretéritos, cualquier análisis histórico demostraría fácilmente la falacia de tal supuesto. Desde los albores del formativo cultural andino, migraciones, guerras, rutas comerciales y expansiones coloniales la han transformado sustancialmente.

Hacia finales del siglo XIX, la música andina pasó a ser motivo de investigación y especulación dentro de la academia. Pioneros de la musicología sobre los Andes, como José Castro, Leandro Alviña o los esposos franceses Marguerite y Raoul D'Harcourt, en los albores del siglo XX intentaron sistematizar la variedad musical en los Andes, recopilando material empírico para cotejarlo con informaciones históricas y etnográficas. A la sazón, los D’Harcourt clasificaron los géneros musicales andinos, sobre la base de su función social, en cantos 
religiosos, lamentaciones funerarias, canciones de amor como los harawis, canciones de despedida, canciones pastorales, etc. (D'Harcourt, 1925, p. 169). José María Arguedas, en cambio, diferenció dos coordenadas en la música andina: una geográfica que delimitaba zonas culturales (Áncash-Huánuco, huanca o chanka) y otra que remite al contexto étnico-cultural de los productores: indios o mestizos (1977, p. 13; 1986, p. 57). Siguiendo la posta dejada por Arguedas, los hermanos Edwin, Luis y Rodrigo Montoya ampliaron la clasificación de áreas culturales quechuas estableciendo ocho zonas - Qorilazo, Cusco Bajo, Puno, Ayacucho, Junín, Áncash o Huaylas, Áncash o Conchuco-, cada una de ellas, a su vez, dividida en sectores señoriales e indígenas (1987, pp. 22-23). Como muestran dichos estudios, la música andina presentaba una variedad muy amplia de condicionamientos culturales, ya sea en ambientes bucólicos y prístinos o en entornos citadinos a lo largo de la cordillera.

Con la construcción de vías de comunicación terrestre y la llegada de la radio a comienzos del siglo XX, la música de los Andes volvió a sufrir una serie de transformaciones. Sus estructuras abiertas se amoldaron a extensiones y sonoridades según lo que permitían los formatos (Mendívil, 2014, p. 388) y los diálogos con otras culturas musicales se hicieron más frecuentes. Así, nuevos instrumentos - como el saxofón - fueron asimilados dentro de los conjuntos (Romero, 1985, p. 268). Hacia mediados del siglo pasado, con la expansión de la radio y la televisión, la música andina comenzó a mudar formas y contenidos más radicalmente. En la primera mitad del siglo XX las formas musicales andinas se habían visto seriamente afectadas por discursos nacionalistas de una élite urbana y por los nuevos condicionamientos tecnológicos con que se enfrentaban en la gran urbe limeña. Pero, con el nacimiento de un mercado discográfico andino hacia mediados del siglo XX, la popularización —o desfolklorización- de las formas, antaño tradicionales, se aceleró y trastocó la concepción compositiva y performativa al introducir las categorías «compositor» e «intérprete» (Lloréns Amico, 1983, pp. 134-141), un proceso que Arguedas ya había advertido años antes y denominado como el paso de lo mágico a lo popular (Arguedas, 1977, p. 27). Como demuestran los ejemplos apenas citados, es imposible ver la música andina como una pétrea presencia de formas precapitalistas, tercamente incrustadas en la realidad posmoderna. La música de los Andes, como toda música, siempre ha estado en movimiento. Por eso es bueno preguntarse: ¿cuál es el panorama musical andino que existe hoy, después de los cambios demográficos y tecnológicos ocurridos en el mundo hacia finales del siglo pasado? 
Con el afán de responder a dicha interrogante, nosotros, los etnomusicólogos peruanos Julio Mendívil y Raúl R. Romero, editores invitados de Anthropologica y con la colaboración del Instituto de Etnomusicología - IDE, lanzamos una convocatoria sobre estudios relacionados con la música de la región andina. Para ello, buscamos concentrarnos en artículos inéditos con un perfil interdisciplinario, que sean de interés para un público académico más allá de la disciplina de la musicología y que, por tanto, abarquen áreas de las ciencias sociales y las humanidades, como la sociología, la antropología y la historia. Procuramos entonces enfoques novedosos que vincularan la música a los procesos sociales y a los temas que en los últimos años han concentrado la atención de los estudios sobre música en el mundo, como las cuestiones de género, el multiculturalismo, la distinción social, la política y violencia, la etnicidad, las identidades subalternas y el nacionalismo, entre otros. Si bien todos estos temas han sido preponderantes en la literatura etnomusicológica de habla inglesa - y en los estudios sobre la música de los Andes en ese idioma-, en el Perú no han recibido aún la atención que merecen.

El resultado es este número, que reúne un monto considerable de artículos que describen realidades musicales actuales desde diversas perspectivas científicas y en países como Argentina, Colombia y Perú. A grandes rasgos, los artículos muestran tres tipos de contextos, en los cuales la música andina sigue vigente o se instaura ahora como un factor de cohesión social y como un espacio para la negociación de valores culturales: (i) prácticas musicales en contextos llamados tradicionales; (ii) prácticas musicales andinas en la capital peruana, y por último, (iii) prácticas en nuevos contextos como resultado del proceso de deterritorialización desencadenado por aquello que el etnólogo indio Arjun Appadurai ha llamado modernidad desbordada (Appadurai, 1996); es decir, los cambios demográficos y tecnológicos desencadenados por la globalización. Solemos imaginar las músicas con formas tradicionales como realidades atrapadas en un pasado persistente; pero, como demuestran los textos escogidos, las tradiciones musicales andinas no solo exhiben un fuerte presente, sino que se exponen como tradiciones claramente orientadas al futuro.

En el primer rubro, el lector encontrará una aproximación etnográfica a la banda típica, una de las agrupaciones musicales tradicionales de mayor envergadura en las festividades de la provincia de Chumbivilcas, región Cusco. Sobre la base de datos etnográficos y otros provenientes del ciberespacio, Hubert Ramiro Cárdenas Coavoy nos ofrece una mirada profunda a las estrategias con que los habitantes de Chumbivilcas reformulan sus tradiciones con el fin de mantenerlas vigentes. 
En un segundo rubro, los artículos se orientan hacia la presencia andina en la capital y recorre un espectro temporal considerable. Desde los trabajos de José María Arguedas, la existencia de un universo musical andino en Lima ha sido un tema recurrente en los estudios sobre música. Influidos por la impronta arguediana, muchos de estos estudios se han dedicado a constatar el paulatino avance del huayno en la otrora Ciudad de los Reyes a partir de las grandes migraciones de mitad del siglo XX (Arguedas, 1977; Lloréns, 1983; Romero, $1985,2007)$. En un texto que rompe con mitos y enquistadas narrativas, Fred Rohner nos demuestra convincentemente que la presencia andina en la capital fue anterior a lo que imaginamos en las primeras décadas de 1900 y que no solo el huayno agradó en ella, sino también el yaraví o la Danza de las Pallas, tal como demuestran las numerosas grabaciones que se hicieron del género en esos años y las repetidas menciones de la danza en documentos de la época.

Por su parte, y dando un salto cronológico considerable, Pablo Molina nos lleva a reflexionar sobre categorías escurridizas, como «tradicional» y «popular», en el imaginario de músicos provincianos —o hijos de provincianos- que operaban en la capital peruana a comienzos del siglo XXI. Tomando como ejemplo la experiencia del grupo Los Cholos, Molina analiza los criterios según los cuales los integrantes de dicha agrupación construyen su noción de lo tradicional, concluyendo que esta surge como el resultado de una confluencia imaginaria entre sonoridades y ciertas representaciones de lugares, tenidos estos como referentes de las prácticas musicales consideradas originarias. Especial interés despiertan las tensiones descritas por Molina entre la llamada «música latinoamericana» y las formas musicales tenidas por ancestrales.

Cierra este rubro un excelente texto de Fiorella Montero Díaz sobre la llamada «música de fusión» y las nuevas identidades de las clases más pudientes en el territorio peruano. Sobre la base de un trabajo de campo en Lima y balnearios, Montero indaga sobre las reformulaciones culturales de ciertos sectores de las clases altas peruanas en su afán por sentirse partícipes de un destino colectivo patrio. Así, registra cómo jóvenes de familias pudientes interpelan los imaginarios sobre lo nacional y sobre la violencia política vivida por el país en la década de 1980, al combinar elementos musicales de las culturas llamadas subalternas con lenguajes musicales identificados con Occidente o con la cultura de masas globalizada. Como la autora misma afirma, esta «fusión» de elementos musicales diversos permite a los involucrados reforzar la búsqueda de su propio yo político y espiritual, en un país aún sacudido por los procesos traumáticos generados por la guerra interna. 
El último rubro de artículos está relacionado con los procesos de globalización y migración ocurridos en América Latina en las décadas pasadas. Como ambos ejemplos revelan, la migración de individuos o de grupos culturales conlleva siempre a una migración de cultura material — los instrumentos-, de géneros musicales y concepciones sobre cómo producir y consumir la música. De este modo, Esteban Ariel Padin tematiza los procesos de apropiación de cultura andina realizados por grupos de jóvenes citadinos en Buenos Aires como una forma de construir una identidad y una práctica social alternativa a aquellas que impone el capitalismo tardío con sus nociones de consumo y explotación de recursos. Tomando el concepto de «reciprocidad», asociado a las culturas llamadas «originarias», estos jóvenes argentinos, ajenos a los Andes, reinventan sus vínculos históricos asociándolos con un pasado andino imaginario. Poniendo como ejemplo el grupo Sikuris del Arco Iris, el autor da testimonio del importante rol de músicos migrantes bolivianos para la construcción de una identidad antigua, aunque imaginada, en Argentina.

Si Padin nos ilustra sobre apropiaciones de lo andino en la ciudad de Buenos Aires, Juan Carlos Molano Zuluaga lo hace en función de la apropiación de elementos andinos por jóvenes emberá chamí, músicos de rock punk, en zonas del litoral pacífico y zonas adyacentes de Colombia. Remitiéndose a un trabajo de campo sólido, Molano Zuluaga reporta las peripecias de un grupo de jóvenes para negociar sonoridades contraculturales en su comunidad, combinando en el trayecto tanto timbres de guitarra eléctrica distorsionada - que se vinculan con la modernidad exterior - como sonoridades del charango, en un intento por insertarse en la tradición indígena de la cual quieren formar parte.

Aunque está fuera del eje temático de este número, los editores hemos decidido la publicación de un texto del etnomusicólogo brasileño Felipe Trotta con relación a los conflictos que surgen del vínculo entre música y territorio en el imaginario social del país vecino, debido a la actualidad del tema y la alta calidad del texto. Como atestigua Trotta, los medios de comunicación contribuyen a que determinadas músicas sean aceptadas en o excluidas de ciertas esferas sociales. Analizando los lenguajes musicales desarrollados por comunidades urbanas, el autor afirma que la música no es siempre condescendiente y, por tanto, que no solo es un instrumento importante para la construcción de identidades y vínculos territoriales que establece simbologías e imaginarios compartidos por una nación, sino que al mismo tiempo es una fuerza que genera segregaciones sobre la base de actitudes y sentimientos de negación, rechazos, impertinencias y prejuicios con relación a pertenencias territoriales —el barrio, la calle—o de género. Recurriendo 
a géneros musicales brasileños tan variados como el samba, el forró y la música sertaneja, Trotta evidencia las jerarquías simbólicas de la nación brasileña y los conflictos que reproducen sus miembros al momento de encontrarse en el campo social musical del Brasil del siglo XXI.

Esperamos que los artículos compilados en este volumen sirvan para reforzar las numerosas vinculaciones entre la antropología y la música entendida como un proceso social y como un sujeto legítimo de estudio interdisciplinario.

\section{REFERENCIAS BIBLIOGRÁFICAS}

Appadurai, A. (1996). Modernity at large. Cultural Dimensions of Globalization. Minneapolis y Londres: University of Minnesota Press.

Arguedas, J. M. (1977). Nuestra música popular y sus intérpretes. Lima: Mosca Azul y Horizonte.

Arguedas, J. M. (1986). Ensayo sobre la capacidad de creación artística del pueblo indio y mestizo. En J. M. Arguedas (ed.), Nosotros los maestros (pp. 53-63). Lima: Horizonte.

D’Harcourt, M. R. (1925). La musique des Incas et ses survivances. París: Librairie Orientaliste Paul Geuthner.

Lloréns Amico, J. A. (1983). Música popular en Lima: criollos y andinos. Lima: Instituto de Estudios Peruanos; Instituto Indigenista Interamericano.

Mendívil, J. (2014). Huayno. En John D. S. Horn (ed.), Encyclopedia of Popular Music of the World (Vol. Genres: Caribbean and Latin America, pp. 386-392). Londres, New Delhi, Nueva York, Sydney: Bloomsbury.

Montoya, Rodrigo, L. Montoya y E. Montoya (1987). La sangre de los cerros. Antología de la poesía quechua que se canta en el Perú (Vol. 1). Lima: Centro Peruano de Estudios Sociales, Mosca Azul Editores y Universidad Nacional Mayor de San Marcos.

Romero, R. R. (1985). La música tradicional y popular. En La música en el Perú. Lima: Patronato Popular y Porvenir Pro Música Clásica.

Romero, R. R. (2007). Andinos y tropicales. La cumbia peruana en la ciudad global. Lima: Instituto de Etnomusicología, Pontificia Universidad Católica del Perú. 